\title{
Erratum to: Human immunodeficiency virus reverse transcriptase base misincorporations can promote strand transfer
}

\author{
L. Diaz $\cdot$ J. V. Cristofaro $\cdot$ J. J. DeStefano
}

Published online: 28 October 2009

(c) Springer-Verlag 2009

\section{Erratum to: Arch Virol (2000) 145:1117-1131 DOI 10.1007/s007050070113}

Unfortunately in the original publication the "Full-length -Acceptor" and "Full-length +Acceptor" labels were reversed for both the "Low dATP" and "Equal dNTPs" columns. Attached please find the corrected version of Table 1.

Table 1 Compilation of results from mutant colony frequency experiments ${ }^{\mathrm{a}}$

\begin{tabular}{|c|c|c|c|c|c|c|c|}
\hline \multicolumn{4}{|c|}{ Low dATP ${ }^{b}$} & \multicolumn{4}{|c|}{ Equal dNTPs } \\
\hline$\#^{\mathrm{c}}$ & Full-length - Acceptor $^{\mathrm{d}}$ & Full-length + Acceptor & Transfer & $\#$ & Full-length -Acceptor & Full-length + Acceptor & Transfer \\
\hline 1 & 0.140 & 0.094 & 0.182 & 1 & 0.033 & 0.029 & 0.035 \\
\hline 2 & 0.130 & 0.118 & 0.141 & 2 & 0.047 & 0.040 & 0.053 \\
\hline 3 & 0.146 & 0.130 & 0.133 & 3 & 0.025 & 0.025 & 0.021 \\
\hline 4 & 0.103 & 0.100 & 0.091 & 4 & 0.034 & 0.028 & 0.030 \\
\hline Ave. & 0.132 & 0.112 & 0.138 & 5 & 0.048 & 0.040 & 0.052 \\
\hline \multirow[t]{5}{*}{ SD } & 0.020 & 0.017 & 0.037 & 6 & 0.047 & 0.033 & 0.052 \\
\hline & & & & 7 & 0.029 & 0.023 & 0.030 \\
\hline & & & & 8 & 0.034 & 0.028 & 0.036 \\
\hline & & & & Ave. & 0.037 & 0.031 & 0.039 \\
\hline & & & & SD & 0.009 & 0.006 & 0.012 \\
\hline
\end{tabular}

${ }^{a}$ The mutant colony frequency is defined as the number of white or faint blue colonies divided by the total number of colonies

${ }^{\mathrm{b}}$ Equal dNTPs refers to reactions with $100 \mu \mathrm{M}$ of each of the $4 \mathrm{dNTPs}$ while the concentration of dATP was reduced to $1 \mu \mathrm{M}$ for low dATP reactions

${ }^{c}$ Refers to the number of independent experiments performed using the stated conditions

${ }^{\mathrm{d}}$ Full-length refers to DNA products extended to the end of the donor template while transfer products transferred to, and were extended on the acceptor template

The online version of the original article can be found under doi:10.1007/s007050070113.

L. Diaz · J. V. Cristofaro · J. J. DeStefano $(\bowtie)$

Department of Cell Biology and Molecular Genetics,

University of Maryland College Park, College Park, MD, USA

e-mail: jdestefa@umd.edu 